\title{
Pseudohypoaldosteronism type 1
}

INSERM

\section{Source}

INSERM. (1999). Orphanet: an online rare disease and orphan drug data base.

Pseudohypoaldosteronism type 1. ORPHA:756

Pseudohypoaldosteronism type 1 (PHA1) is a primary form of mineralocorticoid resistance presenting in the newborn with renal salt wasting, failure to thrive and dehydration. 